\title{
A Method for Simultaneous Determination of Effective Removal Cross-section for Fast Neutrons and Mass Absorption Coefficient for Gamma Rays
}

\author{
Abdelghany A. El Abd ${ }^{1}$ and Ashraf S. Elkady ${ }^{1,2 *}$ \\ ${ }^{1}$ Department of Reactor Physics, NRC, Egyptian Atomic Energy Authority (EAEA), Cairo, Egypt \\ ${ }^{2}$ Department of Physics, Faculty of Science, King Abdulaziz University, Jeddah, Saudi Arabia
}

Received: August 19, 2014; Accepted: September 30, 2014; Published: October 16, 2014

*Corresponding author: Ashraf S. Elkady, Department of Physics, Faculty of Science for girls, King Abdulaziz University, King Fahd road, P.O. 9470, Jeddah 21413, Saudi Arabia, Tel: +966-543547574; E-mail: aelkady@kau.edu.sa

\begin{abstract}
A method for determining the effective removal cross section $\left(\sum_{\mathrm{R}}\right)$ of fast neutrons and mass absorption coefficient $\left(\mu_{\mathrm{R}}\right)$ for gamma rays at energies $661.6 \mathrm{keV}$ and $1332.5 \mathrm{keV}$ is proposed. It is based on relating the ratio (R) of $\sum_{\mathrm{R}}$ to $\mu_{\mathrm{R}}$ at $661.6 \mathrm{keV}$ and $1332.5 \mathrm{keV}$ to effective atomic number $\left(\mathrm{Z}_{\text {eff }}\right)$ for elements, compounds, composite materials and alloys. It is shown that the $\mathrm{R}$-values versus $\mathrm{Z}_{\text {eff }}$ for the most studied materials lie on two master curves. The method was tested by determining $\sum_{\mathrm{R}}$ and $\mu_{\mathrm{R}}$ for several materials. There is a good agreement between results obtained from the present developed method and the traditional method. Some deviations from the values obtained from the traditional method are discussed as well.
\end{abstract}

Keywords: Effective removal cross-section; Mass absorption coefficient; Fast neutrons; Gamma rays; Composite materials; Alloys

\section{Introduction}

The study of photon and neutron interactions with matter is an important issue for several applications, e.g. in industry, medical radiation dosimetry, security inspections, radiation shielding and nuclear engineering materials. In this aspect, an interdisciplinary science between nuclear physics and materials science emerges, which can much help in engineering novel materials for the required application. Mass attenuation coefficient, $\mu_{R}\left(\mathrm{~cm}^{2} / \mathrm{g}\right)$, effective atomic number $\left(\mathrm{Z}_{\text {eff }}\right)$, effective electron density, and photon mean free path are the most important quantities for determining the penetration of X-ray and gamma rays in matter. Theoretical values of the mass attenuation coefficients for elements, compounds and mixtures (composites) from $1 \mathrm{keV}$ to $100 \mathrm{GeV}$ can be obtained using WinXCom software [1]. Besides, the scattering and absorption of X-ray and gamma radiation in matter are related to the densities and atomic numbers of its elemental constituents. However, when such scattering and absorption take place in composite materials, it is then related to the density and the effective atomic number $\left(\mathrm{Z}_{\text {eff }}\right)$. $\mathrm{Z}_{\text {eff }}$ is introduced to describe the properties of composite materials in terms of equivalent elements. Values of the effective atomic number for many composite materials and alloys have been reported [2-6].
The effective removal cross-section, $\sum_{\mathrm{R}}\left(\mathrm{cm}^{2} / \mathrm{g}\right)$ is the probability that a fast or fission energy neutron undergoes a first collision, which removes it from the group of penetrating, uncollided neutrons. It is considered to be approximately constant for neutron energies between 2 and $12 \mathrm{MeV}$ [7]. To use the concept of $\sum_{R}$, the shielding material under investigation should contain some scattering atoms. However, when there are no scattering atoms, another quantity i.e. the total mass neutron cross-section $\sum_{\mathrm{T}}\left(\mathrm{cm}^{2} / \mathrm{g}\right)$ is used. The observed value of the $\sum_{\mathrm{R}}$ is roughly $2 / 3$ of $\sum_{\mathrm{T}}$ for neutrons having energies in the range of 6-8 MeV [8].

Non-Destructive Testing (NDT) of materials is a well-known technique applied in several fields such as inspection of luggage and containers. NDT methods are mainly based on gamma or X-ray scanners, which produce high resolution images. In addition, photons inspection provides materials recognition when traditional transmission measurements at fixed energy are implemented with special technologies as in the case of the so-called "dual energy radiography", "backscattering imaging" or "computed tomography" [7-9]. Materials recognition in such applications is based on the atomic number $\mathrm{Z}$ dependence of the relevant photon absorption coefficients: it is a well-established method at low photon energy where the photoelectric effect dominates, while it becomes critical for increasing photon energy, as it is required in order to increase the penetration of radiation to inspect thick objects [8-10]. A drawback in utilizing photon-based inspection approaches is that when the photon penetration is not sufficient, the object's image appears black. Thus, developing new approaches to overcome the latter problem is a concern in security inspections.

Therefore, in most cases when photon irradiation is unable to disentangle the problem of inspections, the use of neutrons as probing radiation has been often proposed. To this end, sophisticated techniques have been developed in order to enhance materials recognition, especially for low-atomic-number materials, in an effort to optimize the detection of explosives and drugs in customs operation. Examples of such developments 
are represented by the "combined fast-neutron and gammaradiography" and the "fast neutron resonance radiography" [11-15], or by detection of neutron induced gamma rays [15]. Combined fast-neutron and gamma radiography systems [9] perform materials recognition by transmission measurements of fast neutrons and gamma rays [16,17]. Neutrons and gamma rays are obtained from either separate sources such as $14 \mathrm{MeV}$ neutrons (produced by a D+T generator) and gamma rays from an intense ${ }^{60} \mathrm{Co}$ radioactive source [16], or from the same source such as ${ }^{252} \mathrm{Cf}[17,18]$.

It was shown that the ratio of the effective removal crosssection for fast neutrons to the mass absorption coefficient of gamma rays, $\mathrm{R}$ can be utilized for the purpose of non-destructive testing for materials recognition $[11,12,15,17,18]$. However, this ratio was not applied before for determining the effective removal cross-section and the mass absorption coefficient for any material.

The present work aims at developing a simple method based on using the ratio (R) of $\sum_{\mathrm{R}}$ to $\mu_{\mathrm{R}}$ at $661.6 \mathrm{keV}$ and $1332.5 \mathrm{keV}$, for elements for determining $\sum_{\mathrm{R}}$ and $\mu_{\mathrm{R}}$ with the knowledge of $\mathrm{Z}_{\text {eff }}$ for any material.

\section{Theory}

The mass absorption coefficient for gamma rays, $\mu_{R}$ and the effective removal cross-section for fast neutrons, $\sum_{\mathrm{R}}$ can be calculated for mixtures, alloys and compounds, with the knowledge of the weight percentages $\mathrm{w}_{\mathrm{i}}$, and the values of $\mu_{\mathrm{R}}$ and $\sum_{\mathrm{R}}$ of the constituting elements. This is achieved by the following simple addition rules $[7,19]$ :

$$
\begin{aligned}
& \mu_{R}=\sum_{i} w_{i}\left(\mu_{R}\right)_{i} \\
& \text { and } \\
& \sum_{R}=\sum_{i} w_{i}\left(\sum_{R}\right)_{i}
\end{aligned}
$$

for gamma rays and fast neutrons, respectively.

It was proposed that the following empirical formulas [19]:

$$
\begin{aligned}
& \sum_{R}=0.21 A^{-0.56} \mathrm{~cm}^{2} \mathrm{~g}^{-1} \\
& \sum_{R}=0.00662 A^{-1 / 3}+0.33 A^{-2 / 3}-0.211 A^{-1} \mathrm{~cm}^{2} \mathrm{~g}^{-1}(A>12) \\
& \sum_{R}=0.190 \mathrm{Z}^{-0.743} \mathrm{~cm}^{2} \mathrm{~g}^{-1}(Z \leq 8) \\
& \text { and } \sum_{R}=0.125 \mathrm{Z}^{-0.565} \mathrm{~cm}^{2} \mathrm{~g}^{-1},(Z>8)
\end{aligned}
$$

Can be used to determine $\sum_{\mathrm{R}}$ as a function of the atomic weight $\mathrm{A}$ and the atomic number, $\mathrm{Z}$.

The effective atomic number for composites, compounds and alloys for gamma rays can be determined as follows [20]:

The total photon interaction cross section, $\sigma_{m^{\prime}}$ per molecule can be written

$$
\sigma_{m}=\sum_{i} \sigma_{i} n_{i}
$$

where $n_{i}$ is the number of atoms of the $\mathrm{i}^{\text {th }}$ constituent element, and $\sigma_{\mathrm{i}}$ is total photon interaction cross section per atom of element i. The total number of atoms in the compound $\mathrm{n}$ is given by:

$$
n=\sum_{i}
$$

Suppose that the cross section per molecule can be written in terms of an effective (average) cross section, $\sigma_{a^{\prime}}$ per atom and an effective (average) cross section, $\sigma_{e^{\prime}}$ per electron as

$$
\sigma_{m}=n \sigma_{a}=n Z_{e f f} \sigma_{e}
$$

Eq. (9) can be regarded as the definition of the effective atomic number. Essentially, it assumes that the actual atoms of a given molecule can be replaced by an equal number of identical (average) atoms, each of which having $\mathrm{Z}_{\text {eff }}$ electrons. From Eqs. 7 and 9 one obtains

$$
\begin{aligned}
\sigma_{a} & =\left(\sum_{i} n_{i} \sigma_{i}\right) / n \\
\sigma_{e} & =\left(\sum_{i} n_{i} \sigma_{i} / Z_{i}\right) / n
\end{aligned}
$$

It follows from the last equality of Eq. (9) that the effective atomic number can be written as the ratio between the atomic and electronic cross sections:

$$
Z_{e f f}=\sigma_{a} / \sigma_{e}=\left(\sum_{i} n_{i} \sigma_{i}\right) /\left(\sum_{i} n_{i} \sigma_{i} / Z_{i}\right)
$$

Eq. (12) is then the basic relation for calculating the effective atomic number of a chemical compound.

A more general expression for $Z_{\text {eff }}$ can be obtained by introducing the molar fraction, $\mathrm{f}_{\mathrm{i}}$ (sometimes expressed in units of atomic percent, at.\%). For a chemical compound, one has

$$
f_{i}=n_{i} / \sum_{i} n_{i}=n_{i} / n
$$

where $\Sigma_{\mathrm{i}} \mathrm{f}_{\mathrm{i}}=1$. Rewriting Eq.12 in terms of $\mathrm{f}_{\mathrm{i}}$ one has

$$
Z_{\text {eff }}=\left(\sum_{i} f_{i} \sigma_{i}\right) /\left(\sum_{i} f_{i} \sigma_{i} / Z_{i}\right)
$$

Eq. (14) is then the basic relation for calculating the effective atomic number for all types of materials, compounds as well as composites.

The atomic cross section, $\sigma_{i}$ of the $i^{\text {th }}$ constituent element is related to the corresponding mass attenuation coefficient, $(\mu / \rho)_{i^{\prime}}$ through the relation

$$
\sigma_{i}=(\mu / \rho)_{i} A_{i} / N_{A}
$$

where $A_{i}$ is the atomic mass, and $N_{A}$ is the Avogadro's constant. Inserting expression (15)

for $\sigma_{\mathrm{i}}$ in the eq. 14 gives

$$
Z_{\text {eff }}=\left(\sum_{i} f_{i} A_{i}(\mu / \rho)_{i}\right) /\left(\sum_{i} f_{i}(\mu / \rho)_{i} A_{i} / Z_{i}\right)
$$

Eq. (16) can be used for calculating the effective atomic number for both compounds and composites in terms of the mass absorption coefficients.

\section{Results and Discussions}

The physical data of most elements, atomic masses, mass 
removal cross-sections $\Sigma_{R^{\prime}}$ and mass absorption coefficients for gamma rays at $661.6 \mathrm{keV}$ and $1332 \mathrm{keV}$ for elements needed for the calculations $[1,7,8,19]$, were prepared and stored in an Excel spread sheets. The equations written above were implemented in the sheets. They were used to calculate mass absorption coefficients, effective removal cross-sections and effective atomic numbers for the chosen materials.

The estimated ratios of effective removal cross section to mass absorption coefficients at the gamma ray energies 661.6 $\mathrm{keV}$ and $1332 \mathrm{keV}$ for most elements (R), as well as effective removal cross section versus atomic number for elements $(\mathrm{Z}=1$ 92) are shown in Figure 1. As one can see, the R-values at 1332.5 $\mathrm{keV}$ are higher than those at $661.6 \mathrm{keV}$.

The R-values and $\mathrm{Z}_{\text {eff }}$ were calculated for some compounds, composites and alloys. These are : $\mathrm{H}_{2} \mathrm{O}, \mathrm{B}_{4} \mathrm{C}, \mathrm{CO}, \mathrm{CO}_{2}, \mathrm{MgO}, \mathrm{MgCO}$, $\mathrm{SO}_{3}, \mathrm{MgCO}_{3}, \mathrm{NaCl}, \mathrm{SO} 2, \mathrm{NaO}, \mathrm{Na}_{2} \mathrm{O}, \mathrm{SiO}_{2}, \mathrm{P}_{2} \mathrm{O}_{5}, \mathrm{Al}_{2} \mathrm{O}_{3}, \mathrm{CaO}, \mathrm{CaO}_{3^{\prime}}$ $\mathrm{TiO}_{2}, \mathrm{MnO}_{2}, \mathrm{~K}_{2} \mathrm{O}, \mathrm{FeO}, \mathrm{Fe}_{2} \mathrm{O}_{3}, \mathrm{NiO}, \mathrm{CuO}, \mathrm{ZnO}, \mathrm{RbO}, \mathrm{SrO}, \mathrm{H}-\mathrm{Li}$, $\mathrm{H}_{2} \mathrm{Li}, \mathrm{H}_{3}-\mathrm{Li}, \mathrm{H}_{4} \mathrm{Li}, \mathrm{HB}, \mathrm{H}_{2} \mathrm{~B}, \mathrm{HBe}, \mathrm{HC}, \mathrm{HO}, \mathrm{CH}_{2} \mathrm{HNa}, \mathrm{Zn}-\mathrm{Cu}-\mathrm{Ni}, \mathrm{Mn}-$ $\mathrm{Zn}-\mathrm{As}$, Zr-Mo-Cd, Ag-Sn-Nd, As-Ga, Mn-Sc, Mn-Zn-Rb, Mn-Zn-Sr, Dy-H, Dy-Lu, Lu-W-Au, Hf-Pb, H-Pb, Sn-Pb, Sn-Pb, Zr-Pb, Zn-Pb, $\mathrm{Sn}-\mathrm{H}$, and $\mathrm{Zr}-\mathrm{H}$. Also, for some of these materials, the R-values and $\mathrm{Z}_{\text {eff }}$ were calculated for different concentrations of their constituents. Figure 2 shows these results along with those for the corresponding elements. As one can see, the $\Sigma_{\mathrm{R}}$ and R-values (calculated relative to $\mu_{\mathrm{R}}$ at $661.6 \mathrm{keV}$ and $1332.5 \mathrm{keV}$ ) coincide with the data for the elements. The calculated values of $\mathrm{Z}_{\text {eff }}$ at $661.6 \mathrm{keV}$ and $1332.5 \mathrm{keV}$ for any of the above mentioned materials were found roughly the same, which implies an energy independence of $\mathrm{Z}_{\text {eff }}$ in the mentioned range of energies. Of worth noting, the values of $\Sigma_{\mathrm{R}}$ and $\mu_{\mathrm{R}}$ (at $661.6 \mathrm{keV}$ and 1332.5 $\mathrm{keV}$ ) for any material can be determined simultaneously. The determination of $\Sigma_{\mathrm{R}}$ and $\mu_{\mathrm{R}}$ is based on the knowledge of the corresponding $\mathrm{Z}_{\text {eff }}$ at either $661.6 \mathrm{keV}$ or $1332.5 \mathrm{keV}$. Namely, once $\mathrm{Z}_{\text {eff }}$ is determined for any material, the table containing the

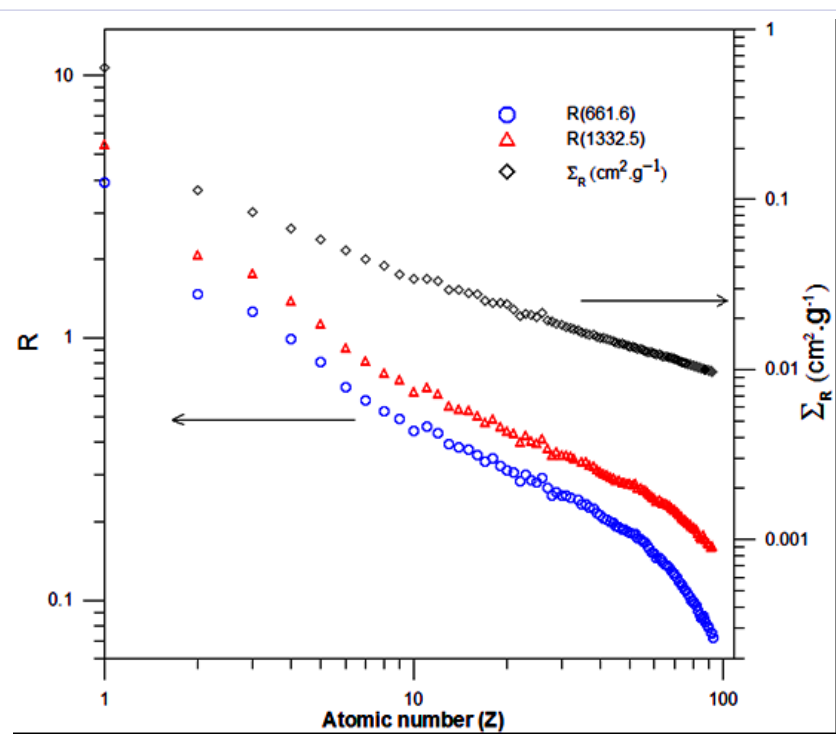

Figure 1: The ratio R at $661.6 \mathrm{keV}, 1332.5 \mathrm{keV}$ and $\Sigma_{\mathrm{R}}$ versus $\mathrm{Z}$ for elements.

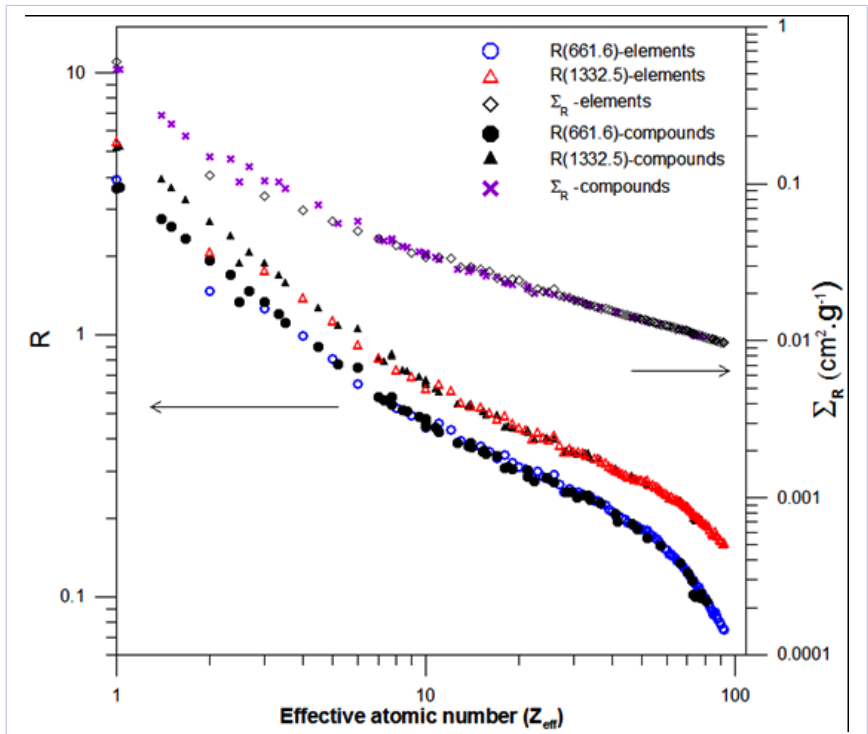

Figure 2: The ratio R and $\Sigma_{\mathrm{R}}$ values for some compounds, composites and alloys versus $\mathrm{Z}_{\text {eff }}$ Results of Figure. 1 are also included.

values of $\mathrm{R}$ including $\mu_{\mathrm{R}}$ at $661.6 \mathrm{keV}$ and $1332.5 \mathrm{keV}$ and $\Sigma_{\mathrm{R}}$ is searched for the closest value to $Z_{\text {eff }}$ At this value of $Z_{\text {eff }}$ the values of $\mu_{\mathrm{R}}$ at $661.6 \mathrm{keV}$ and $1332.5 \mathrm{keV}$ and $\Sigma_{\mathrm{R}}$ are the required ones for such material.

To check the proposed method, the results (for compounds, alloys and mixtures stated above), were used to determine $\Sigma_{\mathrm{R}}$ and $\mu_{R}$ with the knowledge of $Z_{\text {eff }}$ for the following materials [21]: $1 \%$, 5\%, 5.45\%, and 30\% borated polyethylene, 7.5\% Lithium Polyethylene, $78.5 \%$ and $90 \%$ bismuth-loaded polyethylene, borated silicone, flexi-boron shielding, borated HydrogenLoaded castable dry mix, borated hydrogenated mix, boratedlead polyethylene, K-resin, resin 250WD, SUS304, krafton-HB, and premadex. The numbers from 1 to 17 in Table 1 refer to them respectively. The chemical composition of these composites was taken from reference [21]. The obtained results of $\Sigma_{R}$ and $\mu_{R}$ in comparison with the corresponding values calculated by the traditional method (Eqs.1-16) are listed in Table 1. In most cases, good agreement can be noticed between the determined values by the proposed method and the traditional method. Besides, the determined $\Sigma_{\mathrm{R}^{\prime}} \mu_{\mathrm{R}}$ and $\mathrm{Z}_{\text {eff }}$ for these materials along with those shown in Figure 2 were used to determine $\Sigma_{R^{\prime}} \mu_{R}$ for natural Fiber-Plastic (FP), Fiber-Plastic-Lead (FPPb), Cement-Fiber (CF) and Cement-Fiber-Magnetite (CFM) composites, along with the shielding materials of dolomite-sand, barite-barite, magnetite-limonite, ilmenite-ilmenite [22-24]. The chemical compositions shown in Table 2 were taken from references [2224]. The results obtained by the present method along with those obtained by the traditional method are listed in Table 1. One can note good agreements between the values obtained by using the two methods. It can also be noticed in Table 1 for $78.5 \%$ bismuthloaded polyethylene (number "6"), compound number "12", $\mathrm{FPPb}$, Barite-barite, and Magnetite-limonite that, there are two values of $Z_{\text {eff }}$ calculated by the traditional method. These values are obtained from values of $\mu_{\mathrm{R}}$ at $661.6 \mathrm{keV}$ and $1332.5 \mathrm{keV}$. In such case, the table containing the R-values including $\mu_{R}$ at 661.6 
Table 1: $\mu_{\mathrm{R}^{\prime}} \sum_{\mathrm{R}}$ and $\mathrm{Z}_{\text {eff }}$ calculated by the traditional and the present methods.

\begin{tabular}{|c|c|c|c|c|c|c|c|c|}
\hline \multirow{2}{*}{$\begin{array}{l}\text { Compound/ } \\
\text { mixture/alloy } \\
\text { number or name }\end{array}$} & \multicolumn{4}{|c|}{$\mu_{\mathrm{R}^{\prime}} \sum_{\mathrm{R}}$ in $\left(\mathrm{cm}^{2} / \mathrm{g}\right)$, and $\mathrm{Z}_{\text {eff }}$ calculated by traditional method } & \multicolumn{4}{|c|}{$\mu_{R}$ and $\Sigma_{R}$ in $\left(\mathrm{cm}^{2} / \mathrm{g}\right)$, calculated in this work } \\
\hline & $\begin{array}{l}661.6 \\
(\mathrm{keV})\end{array}$ & $\begin{array}{c}1332.5 \\
(\mathrm{keV})\end{array}$ & $\Sigma_{\mathrm{R}}$ & $\mathbf{Z}_{\text {eff }}$ & $661.6(\mathrm{keV})$ & $\begin{array}{c}1332.5 \\
(\mathrm{keV})\end{array}$ & $\Sigma_{\mathrm{R}}$ & $\mathbf{Z}_{\text {eff }}$ \\
\hline 1 & 0.0809 & 0.0576 & 0.0718 & 4.60 & 0.0818 & 0.0583 & 0.0735 & 4.50 \\
\hline 2 & 0.0857 & 0.0611 & 0.1119 & 3.00 & 0.0784 & 0.0559 & 0.104 & 3.00 \\
\hline 3 & 0.0811 & 0.0578 & 0.0728 & 4.53 & 0.0818 & 0.0583 & 0.0735 & 4.50 \\
\hline 4 & 0.0817 & 0.0582 & 0.1001 & 3.22 & 0.0886 & 0.0612 & 0.1029 & 3.43 \\
\hline 5 & 0.0818 & 0.0583 & 0.0927 & 3.50 & 0.0831 & 0.0592 & 0.0926 & 3.50 \\
\hline 6 & 0.1080 & 0.0581 & 0.0358 & $\begin{array}{l}8.40 \\
8.66\end{array}$ & $\begin{array}{l}0.0772 \\
0.0769\end{array}$ & $\begin{array}{l}0.0549 \\
0.0548\end{array}$ & $\begin{array}{l}0.0398 \\
0.0394\end{array}$ & $\begin{array}{l}8.40 \\
8.66\end{array}$ \\
\hline 7 & 0.1110 & 0.0575 & 0.0222 & 15.85 & 0.0741 & 0.0526 & 0.0259 & 15.6 \\
\hline 8 & 0.0803 & 0.0572 & 0.0641 & 5.20 & 0.0727 & 0.0519 & 0.0562 & 5.20 \\
\hline 9 & 0.0778 & 0.0554 & 0.0591 & 5.45 & 0.0727 & 0.0519 & 0.0562 & 5.20 \\
\hline 10 & 0.0850 & 0.0606 & 0.1010 & 3.43 & $\begin{array}{l}0.0831 \\
0.0858\end{array}$ & $\begin{array}{l}0.0592 \\
0.0612\end{array}$ & $\begin{array}{c}0.0926 \\
0.103\end{array}$ & $\begin{array}{l}3.40 \\
3.34\end{array}$ \\
\hline 11 & 0.0799 & 0.0564105 & 0.05507794 & 6.1 & 0.0774 & 0.0552 & 0.0578 & 6.00 \\
\hline 12 & 0.1060 & 0.0587 & 0.0302 & $10.6 / 10.8$ & 0.0774 & 0.0551 & 0.0341 & 10.7 \\
\hline 13 & 0.0934 & 0.0666 & 0.129 & 2.96 & 0.0881 & 0.0628 & 0.1289 & 2.67 \\
\hline 14 & 0.0825 & 0.0587 & 0.0844 & 3.89 & 0.0831 & 0.0592 & 0.0926 & 3.50 \\
\hline 15 & 0.0740 & 0.0522 & 0.0214 & 25 & 0.0718 & 0.0507 & 0.0204 & 24.5 \\
\hline 16 & 0.0850 & 0.0605 & 0.107 & 3.11 & 0.0784 & 0.0559 & 0.104 & 3.00 \\
\hline 17 & 0.0859 & 0.0612 & 0.109 & 3.12 & 0.0784 & 0.0559 & 0.104 & 3 \\
\hline FP & 0.0836 & 0.0595 & 0.0939 & 3.51 & 0.0831 & 0.0592 & 0.0962 & 5.5 \\
\hline FPPb & 0.0912 & 0.0571 & 0.0598 & $5.03 / 4.92$ & 0.0727 & 0.0519 & 0.0562 & 5.2 \\
\hline Dolomite -sand & 0.0776 & 0.0552 & 0.0403 & 8.6 & 0.0769 & 0.0548 & 0.0394 & 5.66 \\
\hline Barite-barite & 0.0779 & 0.0526 & 0.0287 & $12.5 / 12.4$ & 0.0741 & 0.0526 & 0.0285 & 12.7 \\
\hline Magnetite-limonite & 0.0766 & 0.0543 & 0.0365 & $10 / 10.1$ & 0.0767 & 0.0544 & 0.0354 & 10.00 \\
\hline Ilmenite -ilmenite & 0.0755 & 0.0536 & 0.0327 & 11.2 & 0.0776 & 0.0552 & 0.0331 & 10.02 \\
\hline CF & 0.0799 & 0.0568 & 0.0509 & 6.74 & 0.0782 & 0.0558 & 0.0499 & 6.50 \\
\hline CFM & 0.0772 & 0.0548 & 0.0448 & 7.63 & 0.0795 & 0.0522 & 0.0429 & 7.74 \\
\hline
\end{tabular}

Table 2: Weight fractions of some materials used in neutron and $\boldsymbol{\gamma}$-ray shielding.

\begin{tabular}{|c|c|c|c|c|c|c|c|c|}
\hline Element & FP & FPPb & $\begin{array}{l}\text { Dolomite - } \\
\text { sand }\end{array}$ & Barite-barite & $\begin{array}{l}\text { Magnetite- } \\
\text { limonite }\end{array}$ & $\begin{array}{l}\text { Ilmenite - } \\
\text { ilmenite }\end{array}$ & CF & CFM \\
\hline H & 0.0860 & 0.043500 & 0.0082538 & 0.006 & 0.011460 & 0.0064622 & 0.0284 & 0.01780 \\
\hline B & - & 0.149100 & & & & & & 0.09290 \\
\hline $\mathrm{C}$ & 0.5774 & 0.323700 & 0.0839755 & 0.0029 & 0.000076 & & 0.1091 & 0.09457 \\
\hline $\mathbf{0}$ & 0.3333 & 0.128800 & 0.5098378 & 0.33128 & 0.392600 & 0.384150 & 0.4323 & 0.32820 \\
\hline Zn & 0.0010 & 0.000800 & & & & & & \\
\hline $\mathbf{P b}$ & & 0.353700 & & & & & & \\
\hline $\mathrm{Ca}$ & - & - & 0.2611081 & 0.061000 & 0.090200 & 0.053300 & 0.3162 & 0.126800 \\
\hline Mg & - & - & 0.069146 & 0.004200 & 0.003860 & 0.001721 & 0.00602 & 0.005000 \\
\hline $\mathrm{Na}$ & & & 0.002732 & 0.003100 & 0.006800 & 0.006944 & & \\
\hline $\mathbf{K}$ & & & 0.0002803 & & 0.000446 & 0.002232 & & \\
\hline $\mathbf{F e}$ & & & 0.004129 & 0.00300 & 0.421100 & 0.280000 & 0.0294 & 0.274200 \\
\hline $\mathbf{P}$ & & & 0.0000164 & 0.000005 & 0 & 0.000785 & & \\
\hline Si & & & 0.05412 & 0.022441 & 0.0694738 & 0.015600 & 0.0644 & 0.025800 \\
\hline$S$ & & & 0.0004093 & 0.106300 & 0.0002412 & 0.000854 & 0.0043 & 0.001700 \\
\hline Al & & & 0.00064078 & 0.011200 & 0.0043540 & 0.003720 & 0.0151 & 0.006100 \\
\hline Ba & & & & 0.443965 & & & & \\
\hline $\mathrm{Cl}$ & & & & 0.004757 & & & & \\
\hline $\mathrm{Ti}$ & & & & & & 0.243800 & & 0.028700 \\
\hline Mn & & & & & & 0.001550 & & \\
\hline $\mathbf{N i}$ & & & & & & 0.000366 & & \\
\hline $\mathrm{Cr}$ & & & & & & & & 0.001640 \\
\hline
\end{tabular}


$\mathrm{keV}$ and $1332.5 \mathrm{keV}$ and $\Sigma_{\mathrm{R}}$ is searched for the closest value and/ or values to $\mathrm{Z}_{\text {eff }}$. For example, for the compound number "12", the calculated values of $\mathrm{Z}_{\text {eff }}$ are 10.6 and 10.8 and the closest value is 10.7 .

Deviations between $\mu_{\mathrm{R}}$ (at $661.6 \mathrm{keV}$ and $1332.5 \mathrm{keV}$ ) and $\Sigma_{\mathrm{R}}$ determined by the present approach and the traditional method are noticed for some mixtures (Table 3). These can be noticed for $78.5 \%$ bismuth-loaded polyethylene $(0.785 \mathrm{Bi}, 0.184$ C, 0.0309 H), 90\% bismuth-loaded Polyethylene (0.9 Bi, 0.0866 C, 0.0144 $\mathrm{H})$, borated lead polyethylene $(0.8 \mathrm{~Pb}, 0.0122 \mathrm{Ca}, 0.0047 \mathrm{Si}, 0.042$ 0, 0.1071 C, 0.061 B, $0.0179 \mathrm{H}$ ) and Fiber-Plastic-Lead (FPPb) in Table2. These deviations are only for $\mu_{R}$ at $661.6 \mathrm{keV}$. There are no deviations at $1332.5 \mathrm{keV}$. For $\Sigma_{\mathrm{R}^{\prime}}$ deviations do not exceed $17 \%$.

It was noticed that when a composite mixture consisting

Table 3: Deviations of $\mu_{\mathrm{R}}$ at 661.6 and $1332.5 \mathrm{keV}$, and $\sum_{\mathrm{R}}$ determined in this work from traditional method.

\begin{tabular}{|c|c|c|c|}
\hline $\begin{array}{l}\text { Compound/ } \\
\text { mixture/ } \\
\text { alloy } \\
\text { number or } \\
\text { name }\end{array}$ & $\begin{array}{c}\mu_{\mathrm{R}}(\text { this work }) / \\
\mu_{\mathrm{R}}(\text { traditional) } \\
\text { at } 661.6 \mathrm{keV}\end{array}$ & $\begin{array}{c}\mu_{\mathrm{R}}(\text { this work }) / \\
\mu_{\mathrm{R}}(\text { traditional) } \\
\text { at } 1332.5 \mathrm{keV}\end{array}$ & $\begin{array}{l}\sum_{\mathrm{R}}(\text { this work }) / \\
\sum_{\mathrm{R}}(\text { traditional })\end{array}$ \\
\hline 1 & 1.01 & 1.01 & 1.02 \\
\hline 2 & 0.92 & 0.92 & 0.93 \\
\hline 3 & 1.01 & 1.01 & 1.01 \\
\hline 4 & 1.08 & 1.05 & 1.02 \\
\hline 5 & 1.02 & 1.02 & 1.00 \\
\hline 6 & 0.72 & 0.95 & 1.11 \\
\hline 7 & 0.67 & 0.92 & 1.17 \\
\hline 8 & 0.91 & 0.91 & 0.88 \\
\hline 9 & 0.93 & 0.94 & 0.95 \\
\hline 10 & 0.98 & 0.98 & 0.92 \\
\hline 11 & 0.97 & 0.98 & 1.05 \\
\hline 12 & 0.73 & 0.94 & 1.13 \\
\hline 13 & 0.94 & 0.94 & 1.00 \\
\hline 14 & 1.01 & 1.01 & 1.10 \\
\hline 15 & 0.97 & 0.97 & 0.95 \\
\hline 16 & 0.92 & 0.92 & 0.97 \\
\hline 17 & 0.91 & 0.91 & 0.95 \\
\hline FP & 0.99 & 1.00 & 1.02 \\
\hline FPPb & 0.78 & 0.91 & 0.94 \\
\hline $\begin{array}{l}\text { Dolomite - } \\
\text { sand }\end{array}$ & 0.99 & 0.99 & 0.98 \\
\hline $\begin{array}{l}\text { Barite- } \\
\text { barite }\end{array}$ & 0.95 & 1 & 0.990 \\
\hline $\begin{array}{l}\text { Magnetite- } \\
\text { limonite }\end{array}$ & 1.00 & 1.00 & 0.97 \\
\hline $\begin{array}{l}\text { Ilmenite } \\
\text {-ilmenite }\end{array}$ & 1.03 & 1.03 & 1.01 \\
\hline CF & 0.98 & 0.98 & 0.98 \\
\hline CFM & 1.03 & 0.95 & 0.96 \\
\hline
\end{tabular}

of elements having high atomic numbers (with high weight fraction), and the rest of the constituting elements having low atomic numbers, the resultant value of $\mu_{R}$ at $661.6 \mathrm{keV}$ or $\Sigma_{R}$ for the mixture deviates from the traditional method. This is noticed for $78.5 \%$ and $90 \%$ bismuth loaded polyethylene, borated lead polyethylene and Fiber-Plastic-Lead (FPPb) composites. Also, it is noticed that the values of $\mathrm{Z}_{\text {eff }}$ determined for these mixtures at $661.6 \mathrm{keV}$ and $1332.5 \mathrm{keV}$ are slightly different. The deviations noticed in this work can be minimized, e.g. by preparing separate tables containing data for mixtures consisting of elements having high and low atomic numbers. Namely, for every mixture, compound and/or alloy of interest, a separate table should be prepared. These concerns along with electron density calculations, for composites containing light and heavy elements, will be considered in a forthcoming work.

Importantly, the new developed method would be beneficial not only in the area of nuclear physics but in materials science and engineering as well, as it would help a lot in carrying out the necessary calculations for the design of new materials used in radiation shielding and detection. Actually, the recent advances in materials science and nanotechnology allowed for the creation of new materials with superior and enhanced characteristics that qualify them to be used in radiation detection and shielding $[25,26]$. However, in order to understand the behavior of such advanced nanomaterials under the influence of radiation, it is necessary to know preliminary information about their characteristic parameters influencing, e.g. their radiation detection efficiency. Among these important parameters are the nanocomposites mass attenuation coefficients and effective removal cross-sections. Whence, the current developed method for estimating such parameters is important in understanding their radiation detection, or shielding characteristics measured at different radiation doses.

\section{Conclusions}

In this work, a method was developed for determining the effective removal cross-section for fast neutrons and the mass absorption coefficients for gamma rays at $661.6 \mathrm{keV}$ and $1332.5 \mathrm{keV}$ for any compound, alloy and/or composite material. The effective atomic number should be known at one of these energies. In most cases, good agreement is obtained between the values determined by the proposed approach and those obtained by the traditional method.

\section{References}

1. Gerward L, Guilbert N, Jensen KB, Levring H. WinXCom-a program for calculating X-ray attenuation coefficients. Rad Phys and Chem. 2004; 71, 653-4. doi:10.1016/j.radphyschem.2004.04.040

2. Murty VRK. Effective atomic numbers for $\mathrm{W} / \mathrm{Cu}$ alloy for total photon attenuation. Rad Phys and Chem. 2004; 71, 667-9. doi: 10.1016/j. radphyschem.2004.04.046

3. Gowda S, Krishnaveni S, Gowna R. Studies on effective atomic numbers and electron densities in amino acids and sugars in the energy range 30-1333 keV. Nucl Instr and Meth B. 2005; B, 239, 361-9. doi: 10.1016/j.nimb.2005.05.048

4. Icelli O, Erzeneoglu S, Karahan IH, Cankaya G. Effective atomic numbers for CoCuNi alloys using transmission experiments. JQSRT. 


\section{0; 91, 485-91. doi: 10.1016/j.jqsrt.2004.07.006}

5. El-Kateb AH, Rizk RAM, Abdul-Kader AM. Determination of atomic cross-sections and effective atomic numbers for some alloys. Annals of Nuclear Energy. 2000; 27, 1333-43. doi: 10.1016/S03064549(99)00121-8

6. Manohara SR, Hanagodimath SM. Studies on effective atomic numbers and electron densities of essential amino acids in the energy range in energy range $1 \mathrm{keV}-100 \mathrm{GeV}$. Nucl Instr and Meth B. 2007; 258, 321-8. doi: 10.1016/j.nimb.2007.02.101

7. Kaplan MF. Concrete Radiation Shielding. nuclear physics, concrete properties, design and construction. New York, USA: Longman Scientific \& Technical; 1989.

8. Glasstone S, Sesonske A. Nuclear Reactor Engineering. 3rd ed. New York, USA: Springer ; 1986.

9. Vogel H, Haller D. Luggage and shipped goods. Eur J Radiol. 2007; 63(2), 242-53.

10. Ogorodnikov S, Petrunin V. Processing of interlaced images in 4-10 $\mathrm{MeV}$ dual energy customs system for material recognition. Phys Rev ST Accel Beams. 2002; 5, 104701.

11. Overley JC, Chmelik MS, Rasmussen RJ, Schofield RMS, Sieger GE, Lefevre HW. Explosives detection via fast neutron transmission spectroscopy. Nucl Instr and Meth B. 2006; 251 (2) 470-478. doi: 10.1016/j.nimb.2006.04.173

12. Rasmussen RJ, Fanselow WS, Lefevre HW, Chmelik MS, Overley JC, Brown AP, et al. Average atomic number of heterogeneous mixtures from the ratio of gamma to fast-neutron attenuation. Nuclear Instruments and Methods in Physics Research B. 1997; 124(4), 611614. doi: 10.1016/S0168-583X(97)00120-1

13. Rynes J, Bendahan J, Gozani T, Loveman R, Stevenson J, Bell C. Gammaray and neutron radiography as part of a pulsed fast neutron analysis inspection system. Nucl Instr and Meth A. 1999; 422(1-3), 895-899. doi: 10.1016/S0168-9002(98)01039-0

14. Chen G, Lanza RC. Fast neutron resonance radiography for elemental imaging: Theory and applications. IEEE Trans Nucl Sci. 2002; 49: 1919.

15. Eberhardt JE, Rainey S, Stevens RJ, Sowerby BD, Tickner JR. Fast neutron radiography scanner for the detection of contraband in air cargo containers. Appl Radiat Isot. 2005; 63, 179-188.
16. Vourvopoulos G, Womble PC. Pulsed fast/thermal neutron analysis: a technique for explosives detection. Talanta. 2001; 54, 459-468.

17.Viesti G, Cossutta L, Fabris D, Lunardon M, Moretto S, Nebbia, G, et al. Material recognition by using a tagged ${ }^{252} \mathrm{Cf}$ source. Nuclear Instruments and Methods in Physics Research A. 2002; 593 (3), 592596. doi: 10.1016/j.nima.2008.05.024

18. Stevanato L, Caldogno M, Dima R, Fabris D, Lunardon M, Moretto S, et al. A new facility for non-destructive assay using a ${ }^{252} \mathrm{Cf}$ source. Applied Radiation and Isotopes. 2013, 73, 52-59. doi: 10.1016/j. apradiso.2012.11.018

19. Wood J. Computational Methods in Reactor Shielding. New York, USA: Pergamon Press, Inc.; 1982.

20. Manohara SR, Hanagodimath SM, Thind KS, Gerward L. On the effective atomic number and electron density: A comprehensive set of formulas for all types of materials and energies above $1 \mathrm{keV}$. Nuclear Instruments and Methods in Physics Research B. 2008; 266, 39063912. doi: 10.1016/j.nimb.2008.06.034

21. Elmahroug Y, Tellili B, Souga C. Calculation of fast neutron removal cross-sections for different shielding materials. International Journal of Physics and Research (IJPR). 2013; 3(2), 7-16.

22. El-Sayed Abdo A, Ali MM, Ismail MR. Natural fibre high-density polyethylene and lead oxide composites for radiation shielding. Radiation Physics and Chemistry. 2003; 66, 185-195. doi: 10.1016/ S0969-806X(02)00470-X.

23. El-Sayed Abdo A. Calculation of the cross-sections for fast neutrons and gamma-rays in concrete shields. Annals of Nuclear Energy. 2002; 29, 1977-1988. doi: 10.1016/S0306-4549(02)00019-1

24.El-Sayed Abdo A, Ali MAM, Ismail MR. Influence of magnetite and boron carbide on radiation attenuation of cement-fiber/composite. Annals of Nuclear Energy. 2003; 30, 391-403. doi: 10.1016/S03064549(02)00074-9

25.Schrempp-Koops L. Size Effects on the Efficiency of Neutron Shielding in Nanocomposites - a Full Range Analysis. International Journal of Nanoscience. 2013; 12(3), 1350015-22. doi: 10.1142/ S0219581X13500154

26. Sahi S, Chen W. Luminescence enhancement in CeF3/ZnO nanocomposites for radiation detection. Radiation Measurements. 2013; 59, 139. doi: 10.1016/j.radmeas.2013.04.015 